\title{
The utility of focus group interviews to capture dietary consumption data in the distant past: dairy consumption in Kazakhstan villages 50 years ago - ERRATUM
}

M. Schwerin, S. Schonfeld, V. Drozdovitch, K. Akimzhanov, D. Aldyngurov, A. Bouville, C. Land, N. Luckyanov, K. Mabuchi, Y. Semenova, S. Simon, A. Tokaeva, Z. Zhumadilov and N. Potischman

First published online 5 July 2010

doi:10.1017/S2040174410000243, published by Cambridge University Press, 10 May 2010

We regret to announce that the acknowledgements section on page 201 was incomplete. The following sentence should also have been included:

This study was supported by the Intramural Research Program of the NIH and the National Cancer Institute and the Intra-Agency Agreement between the National Institute of Allergy and Infectious Diseases (USA) and the National Cancer Institute, NIAID agreement \#Y2-Al-5077 and NCI agreement \#Y3-CO-5117.

\section{Reference}

1. Schwerin M, Schonfeld S, Drozdovitch V, Akimzhanov K, Aldyngurov D, Bouville A, Land C, Luckyanov N, Mabuchi K, Semenova Y, Simon S, Tokaeva A, Zhumadilov Z, Potischman $\mathrm{N}$. The utility of focus group interviews to capture dietary consumption data in the distant past: dairy consumption in Kazakhstan villages 50 years ago. J Devel Orig Health Dis. 2010; 1, 192-202., doi:10.1017/S2040174410000243. 